\title{
A new device for in-situ pore-water sampling
}

\author{
Andrea Bertolin, Danilo Rudello, Paolo Ugo * \\ Department of Physical Chemistry, University of Venice, Calle Larga S. Marta 2137, I-30123 Venice, Italy
}

Received 3 May 1994; accepted 6 December 1994

\begin{abstract}
A new prototype pore-water sampler is proposed which allows temporal sampling of pore-water from intertidal sediments. The system consists of a nylon device provided with regularly spaced chambers, double filtering ports and pipes for in-situ sample recovering. The field use of this apparatus for determining sulfur species in pore-waters is described; a satisfactory agreement between data obtained by using the proposed in-situ sampler and by core-squeezing in proper experimental conditions is found. Finally, advantages and differences with respect to other in-situ samplers are critically evaluated.
\end{abstract}

\section{Introduction}

The knowledge of pore-water chemistry and its spatial and temporal variation, especially in the case of transitional environments, is of great importance from many viewpoints, in particular to understand the mechanisms of early diagenesis, to evaluate interactions of sediments with macro and micro bentos, and to know the path followed by discharged pollutants.

Many systems for pore-water extraction have been developed and there has been an increasing interest in obtaining reliable and representative experimental results from such a complex matrix. There are two possible approaches: coring of the sediment, and its later squeezing in the laboratory (Masuzawa et al., 1980; Postma, 1981; Ridout, 1981; De Lange, 1984; Luther et al., 1985); or in-situ extraction (Sayles and Wilson, 1973; Nielsen and Postma, 1979; Hines et

\footnotetext{
${ }^{*}$ Corresponding author.
}

al., 1989; Watson and Frickers, 1990; Davis and Galloway, 1993; Hursthouse et a1., 1993). The former procedure may induce compositional changes in the sample due to pressure changes, temperature and redox variations, and solid-solution interactions during extraction, besides transport and storage effects (Carignan et al., 1985; De Lange et al., 1992). The latter procedure, however, although it minimizes many of the previous sampling deficiencies, cannot be considered an artefact-free procedure either; moreover, by adopting in-situ extraction, it is difficult to take pore-water samples deeper than a few metres.

In this paper we describe a new prototype in-situ pore-water sampler developed for the study of temporal and seasonal changes due to redox processes taking place in salt-marshes or shallow-water finegrained sediments. The requirements followed in the project are: no admittance of air, minimal degassing and exiguous adulteration of the sample to avoid sample alteration or contamination. These requirements are particularly important if low concentra- 
tions of easily oxidizable species have to be detected. The results obtained by using the proposed apparatus for field sampling and subsequent laboratory analysis of sulfur species are compared with those from analysis of pore-water obtained by core-squeezing.

\section{Experimental}

All examined pore-waters were sampled in December 1993. The prototype in-situ sampler was inserted, at low tide, in the sediment of a mud-flat located in the central Lagoon of Venice in a site next to the industrial area of Porto Marghera. Previous studies (Menegazzo-Vitturi et al., 1987; Pavoni et al., 1987; Frizzo et al., 1991; Bertolin et al., 1995) indicated that surface sediments from this site were composed of clayey silt ( $50 \%$ carbonates, $25 \%$ silico-clastic fraction, $25 \%$ illite and montmorillonite) with a mean organic carbon content of about $3 \%$ and pore-water content of about $30 \%$; moreover, they are characterized by high concentrations of heavy metals deriving from industrial wastes. The core, used for obtaining pore-water by the squeezing procedure, was extracted with a handle piston corer in proximity to the site were the in-situ sampler has been previously set. Pore-water from the core was obtained in laboratory operating in a nitrogen glove-box, by using a Reeburgh-type squeezer (Howarth et al., 1983); samples were then filtered through a $0.45 \mu \mathrm{m}$ Millipore filter unit. All analyses were carried out at room temperature $\left(22 \pm 1 \mathrm{C}^{\circ}\right)$ soon after obtaining the pore-water samples, using a cell, previously degassed with nitrogen, completely filled with the sample, avoiding any contact with the air during the sample transfer.

Sulfate was analyzed using the turbidimetric method (APHA, 1985). Sulfide, sulfite and thiosulfate were determined with cathodic stripping voltammetry, slightly modifying the procedures described in the literature (Metrohm, 1979; Luther et al., 1986). In particular sulfide was determined in the crude sample at its own natural $\mathrm{pH}$ (which usually ranged from 7 to 7.5 ) without degassing the solution; preliminary tests indicated that S(-II) concentrations values determined in such conditions compare well with those in alcaline solutions, according to the literature procedures. Thiosulfate and sulfite were analyzed in acid conditions ( $\mathrm{pH} \mathrm{4)}$ after addition of acetic acid, degassing with nitrogen up to complete elimination of $\mathrm{H}_{2} \mathrm{~S}$; no detectable $\mathrm{SO}_{3}^{2-}$ was determined in any of the examined samples. A Princeton Applied Research polarograph model 384B associated with a model $303 \mathrm{~A}$ static mercury drop electrode (operating in SDME mode) was used for the electrochemical measurements. Differential Pulse Voltammetry was performed at a $20 \mathrm{mV} / \mathrm{s}$ scan rate, $0.07 \mathrm{~V}$ pulse height and $0.2 \mathrm{~s}$ step time. Initial potential for the analysis of $\mathrm{S}(-\mathrm{II})$ is $-0.4 \mathrm{~V}$, final potential is $-1 \mathrm{~V}$; initial potential for the analysis of thiosulfate and sulfite is $0 \mathrm{~V}$, final potential is $-0.8 \mathrm{~V}$.

$E$ h values of sampled pore-waters were measured with an AMEL HD-8602 $E$ h-meter equipped with a platinum disc electrode and an internal $\mathrm{Ag} / \mathrm{AgCl}$ reference electrode ( $E$ reference $=0.197 \mathrm{~V}$ vs. NHE).

\section{Results and discussion}

The prototype sampler is shown schematically in Fig. 1. It consists of a rectangular base nylon block in which V-shaped chambers (volume $30 \mathrm{ml}$ ), for collecting pore-water, are milled at $10 \mathrm{~cm}$ intervals. The sampling ports $(3 \mathrm{~cm})$ are entirely covered by a Millipore membrane (item 3 in Fig. 1, porosity 0.45 $\mu \mathrm{m}$ ); the inner side of the membrane is protected by a nylon net (item 4 in Fig. 1) which avoids the possible breakdown during sample suction. The prototype developed by us has a total length of about 1 $\mathrm{m}$, but the same project and sampling design can be used for longer devices, with sampling ports at deeper levels. The distance between ports is chosen on the basis of literature considerations (Watson and Frickers, 1990) in order to ensure that the withdrawal of the sample does not alter the concentration at each sampling level by lateral or vertical replenishment. Resorting to a double mouth for each chamber allows the doubling of the filtering surface for each level while minimizing flow perturbation phenomena. A series of silicone tubes (item 5 in Fig. 1; Øinn. $=1 \mathrm{~mm}, \emptyset$ out. $=3 \mathrm{~mm}$ ) connects each chamber with the surface so allowing the collection of pore-waters without removal of the sampler.

The outer side of the Millipore membrane is 
covered by a nylon face plate (item 2 in Fig. 1) with holes $(\emptyset=0.2 \mathrm{~cm}, 40$ holes per ports) drilled in correspondence with each sampling port, so that the total free inlet area of each port is restricted to 1.2 $\mathrm{cm}^{2}$. Each nylon face plate is fixed to the apparatus main frame by four nylon screws. The interruption of the face plates between each port obstructs the formation of preferential vertical paths avoiding percolation of waters belonging to different levels along the sampler walls. The effectivness of this trick has been tested by looking at the possible percolation of a tracer deliberately added to the sediment in which the sampler was previously set. In particular, when $50 \mathrm{ml}$ of a Fuchsine acid solution $(4 \% w / w)$ are poured in the sediment contiguous to the sampler head, the presence of the tracer is detected only in the sample sucked from the first chamber, even three hours (i.e. a quarter of a tidal cycle) after the pouring of the tracer. It was not possible to extend this experiment to longer time lags because of the wash-

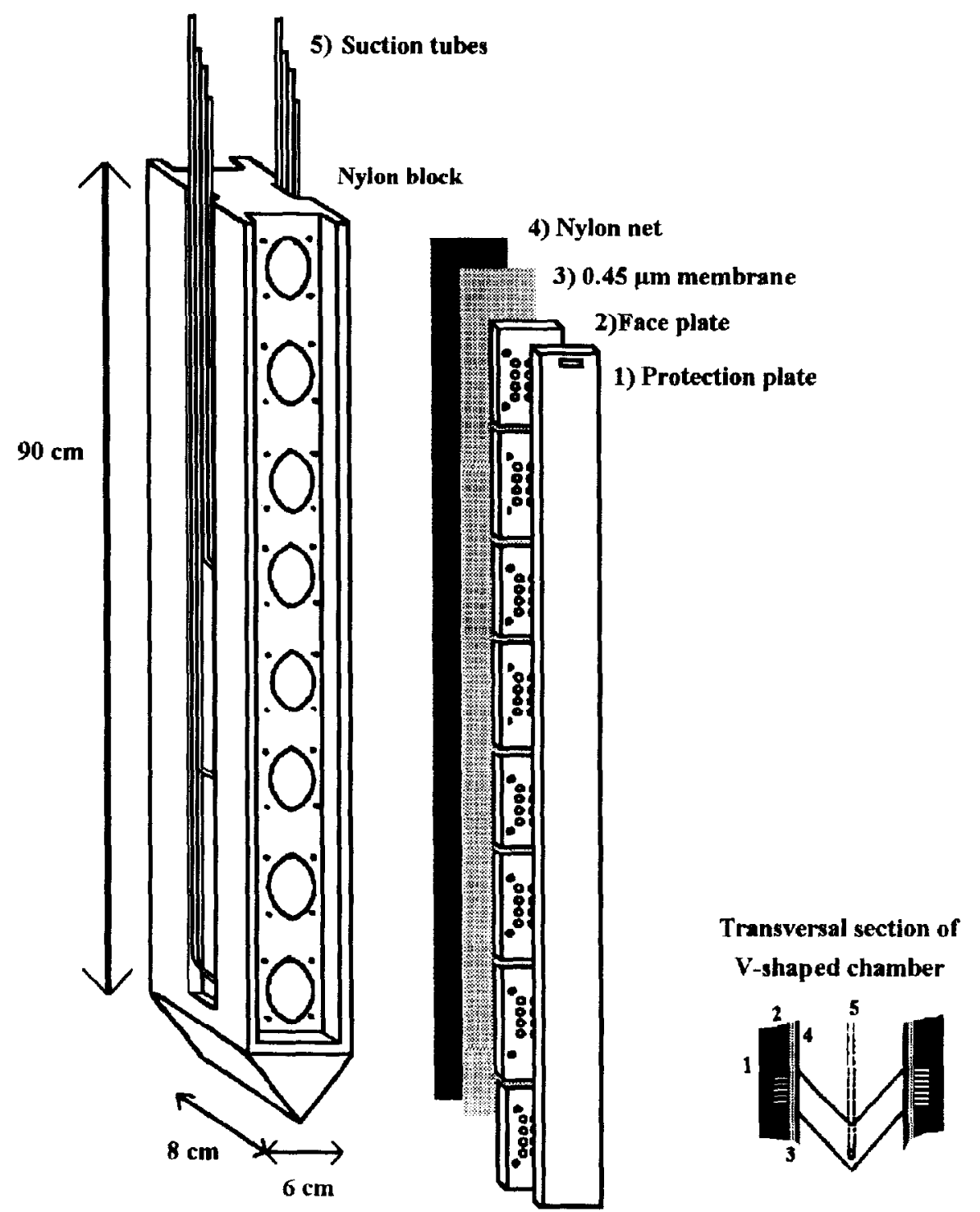

Fig. 1. Schematic diagram of the in-situ pore-water sampler. 
Sulfate

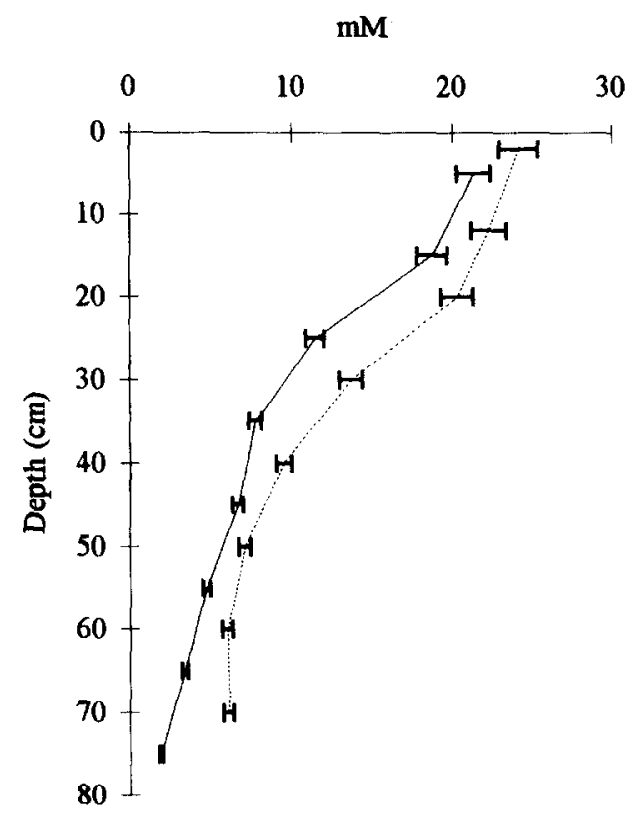

Thiosulfate

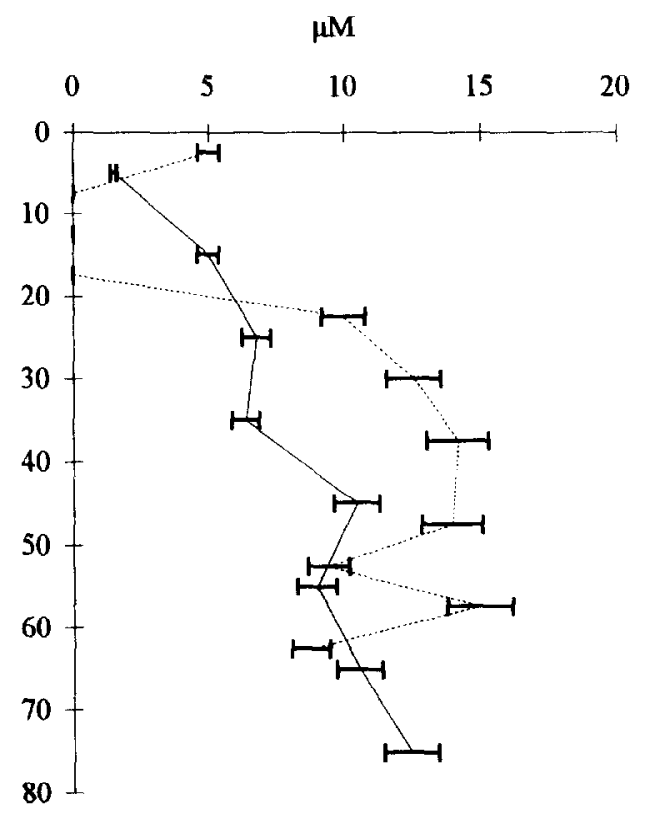

Eh
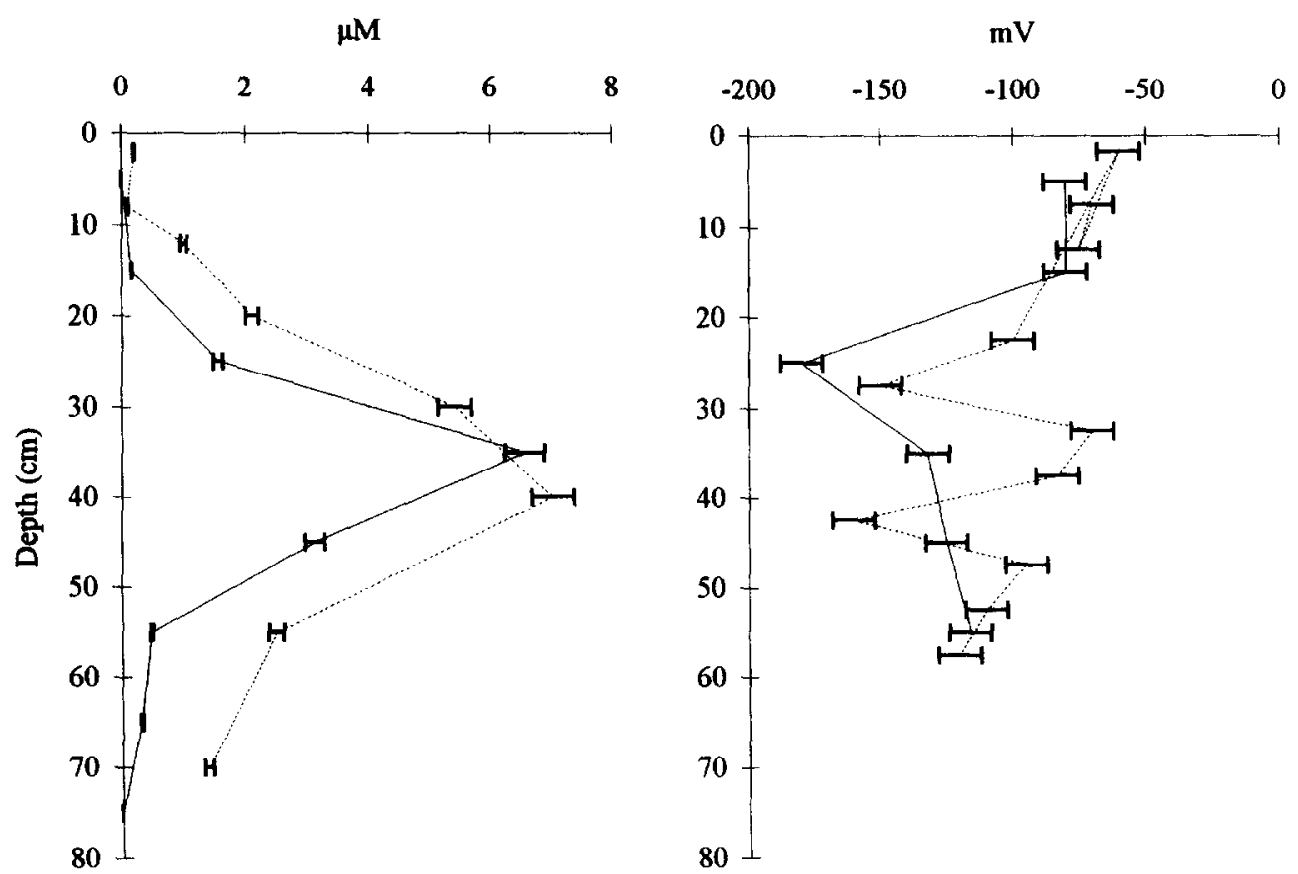

Fig. 2. Concentration profiles for sulfate, tiosulfate, sulfide and $E \mathrm{~h}$, in pore-water sampled by using the proposed in-situ sampler ( - ), and core-squeezing (- ). Error bars refer to the standard deviation of five replicate determinations. 
ing of the tracer from the sediment in high-tide conditions.

The protection plates (item 1 in Fig. 1) are removed only after final setting of the sampler into sediments; residual air present in the chambers is then removed by suction with a hand pump and finally the silicone tubes are sealed by closing a series of stopcocks. Sampling is carried out, after a proper equilibration time (see below), by opening one stopcock and gently sucking with a syringe; the siringe will contain the sample up to the analysis. At the end of the suction no free volume is left inside the syringe which is then sealed by closing a stopcock at the syringe inlet. No further manipulation or filtration of the pore-water is operated: syringes are kept in the dark in a nitrogen atmosphere. All gastight materials are used in order to prevent sulfide from escaping and oxygen from entering during these operations.

Preliminary experiments have shown that an initial waiting period of two weeks is long enough to obtain equilibrium conditions for the sampled porewaters with the sediment environment. If pore-water is sucked and analyzed soon after setting the sampler, higher $\mathrm{SO}_{4}^{2-}$ and lower $\mathrm{HS}^{-}$concentrations are determined than those detected when using sediment squeezing, while a satisfactory agreement is observed for data obtained with the two sampling methods after two weeks poising of the in-situ sampler. The need to wait for about two weeks to equilibrate in-situ samplers after setting, has been also observed by others (Carignan et al., 1985; Davis and Galloway, 1993).

As shown in Fig. 2, the comparison between profiles relevant to concentrations of $\mathrm{SO}_{4}^{2-}, \mathrm{S}_{2} \mathrm{O}_{3}^{2-}$, $\mathrm{S}(-\mathrm{II})$ and $E \mathrm{~h}$ values, determined in pore-waters sampled by the proposed device in equilibrium conditions (full line) and by core squeezing (dotted line) displays good agreement as far as patterns, trends and ranges of values are concerned. $E$ h data measured on both kinds of pore-water samples show satisfactory concordance and are comparable with those measured directly in the sediment by Sfriso and Pavoni (1993), soon after coring.

However, it is worth noting that many concentration values obtained by core-squeezing are slightly higher than the sampler values; this effect is evident for the thiosulfate concentration profile in the $20-50$ cm layer. A "squeezing effect", observed also by others (Edmunds and Bath, 1976; Howes et al., 1985), might be responsable for a release of ions caused by mechanical breaking of soft particles and squeezing of living organisms contained in the sediment (invertebrates, algal fragments, etc.), also because the core in this depth zone showed the presence of evident marsh reeds remains (Bertolin et al., 1995). It can be noted that also other pore-water separation procedures which mechanically stress the sediment, e.g. ultracentrifugation (Edmunds and Bath, 1976; Howes et al. 1985), can cause an increase in the determined concentration with respect to data relevant to pore-water samples obtained by "softer" methods, such as dialysis (Carignan et al., 1985; De Lange et al., 1992).

As far as volumetric recovery is concerned, the volume of pore-water obtained at each sampling level corresponds to the amount of water in about $100 \mathrm{ml}$ of the studied sediment (hypotetically contained in an hemisphere of $2.9 \mathrm{~cm}$ radius facing each port of sampling chambers). Even if the distribution of the perturbated sediment volume can assume an asymmetrical shape and diffuse borders, since such a perturbation is relatively small in volume, we estimated that a resolution of $\pm 4 \mathrm{~cm}$ with respect to the port center can be considered to be a realistic resolution value.

Compared to other in-situ samplers, our device, which adopts a two ports sampling inlet system, seems to be less perturbing of natural pore-waters flows inside the sediment and, in principle, can respond rapidly to concentration changes (e.g. related to tidal cycles). Further studies on the temporal resolution of the device arc at present under study in our laboratory.

The sampler presented here differs from the pioneering apparatus developed by Sayles and Wilson (1973), for pore-water sampling from deep-sea sediments, as well as from the device proposed by Davis and Galloway (1993), for pore-water sampling from lake sediments, in that our prototype does not need to be removed for obtaining the sample. This avoids problems connected with lateral and vertical variability of the determined parameters, which often affect measurements carried out in pore-waters obtained from replicate coring. So far it allows to obtain sequential samples from the same location, and seems 
particularly apt, for instance, for continuously monitoring the release of toxic substances from polluted areas.

The sampler presented here differs also from the systems proposed by Nielsen and Postma (1979), Short et al. (1985) and Hines et al. (1989) since it allows simultaneous sampling at different levels while their systems require more than one device to obtain concentration vs. depth profiles. With respect to the samplers designed for use in intertidal sediments, described by Watson and Frickers (1990) and Hursthouse et al. (1993), it is worth noting that our sampler has been specifically designed to investigate deeper layers involved in the first diagenesis, while those devices have been developed to study watersediment interfacial processes taking place in the first centimeters (or millimeters) of sediment. Moreover, the sampler collection system used in those devices does not avoid the stripping of volatile species, such as hydrogen sulfide, during sample collection.

Finally, we wish to remark that, although the reported results only concern the use of our prototype sampler for determining volatile and easily oxidable sulfur species, if proper materials are used, this apparatus can become suitable also for trace metal sampling. Studies on the application of such a device in association with electroanalytical methods which are able to speciate the redox and complexation state of metal ions such as $\mathrm{Cu}(\mathrm{I})$ and $\mathrm{Cu}(\mathrm{II})$ (Ugo et al., 1993), are in progress in our laboratory.

\section{Acknowledgements}

We wish to thank Dr. G. Rampazzo for useful discussion and two reviewers for suggestions in improving the manuscript.

This work was supported by the project " Sistema Lagunare Veneziano".

\section{References}

APHA, 1985. Standard Methods for the Examination of Water and Wastewater. Am. Public Health Assoc., Washington, DC, $467 \mathrm{pp}$.

Bertolin, A., Frizzo, P. and Rampazzo, G., 1995. Sulphide speciation in surface sediments of the Lagoon of Venice: A geochemical and mineralogical study. Mar. Geol., in press.
Carignan, R., Rapin, F. and Tessier, A., 1985. Sediment porewater sampling for metal analysis: a comparison of tehniques. Geochim. Cosmochim. Acta, 49: 2493-2497.

Davis, A. and Galloway, J.N., 1993. Distribution of $\mathrm{Pb}$ between sediments and pore water in Woods Lake, Adirondack State Park, New York, U.S.A. Appl. Geochem., 8: 51-65.

De Lange, G.J., 1984. Shipboard pressure filtration system for interstitial water extraction. Meded. Rijks Geol. Dienst., 38: 209-214.

De Lange, G.J., Cranston, R.E., Hydes, D.H. and Boust D., 1992. Extraction of pore water from marine sediments: A review of possible artifacts with pertinent examples from the north Atlantic. Mar. Geol., 109: 53-76.

Edmunds, W.M. and Bath, A.H., 1976. Centrifuge extraction and chemical anaysis of interstitial waters. Environ. Sci. Technol., 10: $467-472$.

Frizzo, P., Rampazzo, G. and Molinaroli, E., 1991. Authigenic iron sulphides in recent sediments of the Venice Lagoon (Northern Italy). Eur. J. Mineral., 3: 603-612.

Hines, M.E., Knollmeyer, S.L. and Tugel J.B., 1989. Sulfate reduction and other sedimentary biogeochemistry in a northern New England salt marsh. Limnol. Oceanogr., 34: 578-590.

Howarth, R.W., Giblin, A., Gale, J., Peterson, G.W. and Luther III, G.W., 1983. Reduced sulphur compounds in the pore waters of a new England salt-marsh. Environ. Biogeochem., 35: 135-152.

Howes, B.L., Dacey, J.W.H. and Wakeham, S.G., 1985. Effects of sampling technique on measurements of porewater costituents in salt marsh sediments. Limnol. Oceanogr., 21: 912-914.

Hursthouse, A.S., Iqbal, P.P. and Denman, R.S., 1993. Sampling interstitial waters from intertidal scdiments: an incxpensive device to overcome an expensive problem? Analyst, 118: 146-147.

Luther III, G.W., Giblin, A.E. and Varsolona, R., 1985. Polarographic analysis of sulfur species in marine porewaters. Limnol. Oceanogr., 30: 727-736.

Luther III, G.W., Church T.M., Scudlark, J.R. and Cosman, M., 1986. Inorganic and organic sulfur cycling in salt-marsh pore waters. Science, 232: 746-748.

Masuzawa T., Kanomori, S. and Kitano, Y., 1980. The reversible effect of temperature on the chemical composition of interstitial water of marine sediments. J. Occanogr. Soc. Jpn., 36: 68-72.

Menegazzo-Vitturi, L., Molinaroli, E., Pistolato, M. and Rampazzo, G., 1987. Geochemistry of recent sediments in the Lagoon of Venice. Rend. Soc. Ital. Mineral. Petrol., 42: $59-72$.

Metrohm, 1979. The polarographic determination of sulphide, sulphite and thiosulphate. Metrohm Switzerland Appl. Bull., September.

Nielsen, S. and Postma, D., 1979. An apparatus for temporal sampling without air contact of pore water form swamp sediments. Dan. Gcol. Unders., Arbog: 31-39.

Pavoni, B., Donazzolo, R., Marcomini, A., Degobbis, D, and Orio, A.A., 1987. Historical development of the Venice Lagoon contamination as recorded in radiodated sediment cores. Mar. Pollut. Bull., 1: 18-24. 
Postma, D., 1981. Formation of siderite and vivianite and the pore water composition of a recent bog sediment in Denmark. Chem. Geol., 31: 225-244.

Ridout, P.S., 1981. A shipboard system for extracting interstitial water from deep ocean sediments. IOS, Rep. 121, 13 pp.

Sayles, F.L. and Wilson, T.R.S., 1973. In situ sampler for marine sedimentary pore waters: evidence for potassium depletion and calcium enrichment. Science, 181: 154-156.

Sfriso, A. and Pavoni, B., 1993. Macroalgae and phytoplankton competition in the central Venice lagoon. Environ. Technol., 14: $1-14$.
Short, F.T., Davis, M.W., Gibson, R.A. and Zimmerman C.F., 1985. Evidence for phosporous limitation in carbonate sediments of the seagrass Syringodium filiforme. Estuarine Coastal Shelf Sci., 20: 419-430.

Ugo, P., Moretto, L.M. and Mazzocchin, G.A., 1993. Ion exchange voltammetry of copper ions in chloride media at glassy carbon electrodes modified with polycationic ionomers. Anal. Chim. Acta, 273: 229-236.

Watson, P.G, and Frickers, T.E., 1990. A multilevel, in situ pore-water sampler for use in intertidal sediments and laboratory microcosms. Limnol. Oceanogr., 35(6): 1381-1389. 